\title{
Atomic Structure of Sodium Iron Phosphate Glasses
}

\author{
Bushra M. Al-Hasni ${ }^{\mathrm{a}, \mathrm{b}}$ Gavin Mountjoy ${ }^{\mathrm{a}}$, Emma Barney ${ }^{\mathrm{c}, \mathrm{d}}$ \\ ${ }^{a}$ School of Physical Sciences, University of Kent, Canterbury, CT2 7NH, UK \\ ${ }^{b}$ University of Technology and applied sciences- AL Rustaq, Sultanate of Oman \\ ${ }^{c}$ ISIS Facility, Rutherford Appleton Laboratory, Chilton, Didcot OX11 OQX, UK \\ ${ }^{d}$ Department of Mechanical, Materials and Manufacturing Engineering, University of \\ Nottingham, Nottingham, NG7 2RD, UK
}

\begin{abstract}
The atomic structure of a series of sodium iron phosphate glasses is studied using different experimental techniques: $\mathrm{X}$-ray and neutron diffraction, infrared spectroscopy, extended X-ray absorption fine structure (EXAFS) and X-ray absorption near edge structure (XANES). Detailed information about the atomic pair correlations is obtained. The high resolution of neutron diffraction in real space resolves two P-O distances at $1.48 \AA$ and $1.59 \AA$ as expected. All the glasses are found to consist of a phosphate tetrahedral network with metaphosphate chains and pyrophosphate units, and every phosphate unit is found to have two or three non-bridging oxygen (NBO) links available to coordinate with $\mathrm{Na}$ and $\mathrm{Fe}$ cations. The $\mathrm{Fe}-\mathrm{O}$ coordination number in these glasses is found to decrease from 5.7 to 4.8 with increasing the Fe content, whereas the $\mathrm{Na}$ coordination number of approximately 5 is detected for all the samples.
\end{abstract}

Keywords: EXAFS, FTIR, neutron diffraction, sodium iron phosphate glasses, XANES, X-ray diffraction. 


\section{Introduction}

Although there are limited recorded applications of phosphate glasses due to their poor chemical durability [1], the interest in these glasses has grown up recently. This growth comes as a result of adding cation additives to the phosphate glasses as these additives are found to improve the properties of these glasses. For example, the addition of iron oxides to phosphate glass gives extremely good resistance to hydrolysis [2]. Good chemical durability of iron phosphate glass has opened a huge area of potential applications, such as producing effective laser materials [3] and for vitrification of high-level nuclear waste (HLW) $[4,5]$. This has been recognised as due to the replacement of P-O$\mathrm{P}$ bonds by the Fe-O-P bonds and the strong cross-linking of the $\mathrm{P}$ chains by the Fe ions. The $\mathrm{Fe}^{3+}$ cation is suggested to strengthen the network of the phosphate glasses and most likely to act as a network former [6]. Although the majority of HLW, which is highly radioactive and heat-generating, is currently immobilised by vitrification in borosilicate glasses, iron phosphate glasses are found to be more effective [7]. This is because borosilicate glasses have some shortcomings which include a narrow capacity to immobilise certain elements, e.g., P, S, Mo, noble metals and halogen [7]. $\mathrm{P}_{2} \mathrm{O}_{5}-\mathrm{Al}_{2} \mathrm{O}_{3}-\mathrm{Na}_{2} \mathrm{O}$ glasses have been used in the immobilisation of Russian HLW, and currently interest is shown in the $\mathrm{P}_{2} \mathrm{O}_{5}-$ $\mathrm{Fe}_{2} \mathrm{O}_{3}$ system due to its thermal properties, chemical durability, waste-loading and elemental solubility properties [8]. $\mathrm{Fe}_{2} \mathrm{O}_{3}-\mathrm{P}_{2} \mathrm{O}_{5}$ glasses with high $\mathrm{Fe}_{2} \mathrm{O}_{3}$ content have received a lot of attention as they display short-range antiferromagnetic ordering at low temperatures [9]. In addition, iron phosphate glass fibres have been found to own excellent modulus values and strength that 
permit them to rival E-glass [10]. Such glasses are also of extensive importance because of their semiconducting properties arising from the presence of both oxidation states $\mathrm{Fe}^{2+}$ and $\mathrm{Fe}^{3+}[11,12]$.

An investigation of sodium iron phosphate glass proved that the addition of $\mathrm{Na}$ to iron phosphate glasses has an effect on the chemical durability, glass transition temperature and thermal expansion coefficient [13]. Additionally, $\mathrm{Na}-\mathrm{Fe}$ phosphate glasses were found to have a good chemical durability in water and saline solution [6]. Yu et al. [6] reported that the P-O network becomes stronger with increasing $\mathrm{Fe}_{2} \mathrm{O}_{3}$ or $\mathrm{Na}_{2} \mathrm{O}$ content, however, several years ago most published articles about phosphate glasses for waste immobilisation placed emphasis on $\mathrm{Pb}-\mathrm{Fe}$ phosphate glasses $[14,15]$. The effect of modifier additions, including $\mathrm{Na}$ on the thermal properties, chemical durability, oxidation state and structure of Fe-P glasses has been recently studied by Bingham et al. [16], however, concern remains regarding studying the structure of $\mathrm{Na}-\mathrm{Fe}$ phosphate glasses. This is significant in order to understand the effect of network modifier $\mathrm{Na}^{+}$as well as the environment of iron in different compositions which can be relevant to achieving the immobilisation of nuclear wastes.

This work is directed toward sodium iron phosphate glasses with composition $(40-\mathrm{x}) \mathrm{Na}_{2} \mathrm{O} \cdot \mathrm{xFe}_{2} \mathrm{O}_{3} \cdot 60 \mathrm{P}_{2} \mathrm{O}_{5}$ where $\mathrm{x}=10,20,30$ and 40 . These compositions have been chosen as they represent the glass-forming region as reported by Parsons and Rudd [17]. The O/P ratio in these glasses is in the range of metaphosphate to pyrophosphate compositions [3]. A range of techniques were therefore applied to sodium iron phosphate glasses, including X-ray and neutron diffraction, X-ray absorption spectroscopy, ${ }^{57}$ FTIR spectroscopy and X-ray fluorescence spectroscopy. Different cations may give rise to the structural 
differences in either crystalline or glasses samples [18]. The detailed investigation of these particular compositions is helpful in presenting a thorough understanding and the determination of the changes induced by adding $\mathrm{Fe}$ or $\mathrm{Na}$. Hoppe et al. $[19,20]$ reported that both the type and the concentration of metal ion have been found to affect the $\mathrm{P}-\mathrm{O}_{\mathrm{b}}$ and $\mathrm{P}-\mathrm{O}_{\mathrm{nb}}$ bond distances and the differences between the two bond distances become smaller as the attractive forces of metal cation increase.

Previous infrared and Mössbauer spectroscopy measurements [21] of $\mathrm{Na}-\mathrm{Fe}$ phosphate glasses showed that the increase in $\mathrm{Na}_{2} \mathrm{O}$ or $\mathrm{Fe}_{2} \mathrm{O}_{3}$ content led to a change of iron coordination from $\mathrm{FeO}_{6}$ to $\mathrm{FeO}_{4}$. Moreover, X-ray photoelectron and Mössbauer spectroscopy indicated that $\mathrm{Fe}^{2+}$ and $\mathrm{Fe}^{3+}$ were present in the glasses and improve the chemical durability with increasing $\mathrm{Fe}^{3+}$ concentration [6].

\section{Method}

\subsection{Glass preparation}

Raw materials including sodium pyrophosphate $\left(\mathrm{Na}_{4} \mathrm{P}_{2} \mathrm{O}_{7}\right)$, ammonium phosphate monobasic $\left(\mathrm{NH}_{6} \mathrm{PO}_{4}\right)$ and iron oxide $\left(\mathrm{Fe}_{2} \mathrm{O}_{3}\right)$ are mixed in a $\mathrm{Pt} / \mathrm{Au}$ $(5 \% \mathrm{Au} / 95 \% \mathrm{Pt})$ crucible. The mixtures are melted at $1,200^{\circ} \mathrm{C}$ for two hours in a Carbolite AAF 1200 Furnace. After two hours the samples are quenched to the room temperature in air by pouring on to a copper plate. Four compositions of the $\mathrm{Na}_{2} \mathrm{O}-\mathrm{Fe}_{2} \mathrm{O}_{3}-\mathrm{P}_{2} \mathrm{O}_{5}$ system have been investigated in this work and are listed in Table 1 with their densities, which have been measured using a helium micropycnometer. Moreover, other initial sample characterisations have been 
performed using TGA/DTA to measure the onset glass transition temperatures, $\mathrm{T}_{\mathrm{g}}$, which are reported in Table 1 . The $\mathrm{T}_{\mathrm{g}}$ values are found to be in agreement with those reported by Parsons and Rudd [17]. Both the density and the glass transition temperature increased with increasing iron oxide as expected, however, a maximum is observed at around the $30 \% \mathrm{Fe}_{2} \mathrm{O}_{3}$ content after which $\mathrm{T}_{\mathrm{g}}$ falls, as observed by [17]. The $\mathrm{T}_{\mathrm{g}}$ value decreased slightly in the sample with $40 \% \mathrm{Fe}_{2} \mathrm{O}_{3}$ which has been reported to have the best chemical durability [22]. This effect can be attributed to the inclusion of Fe ions in the phosphate backbone and indicates the structural changes.

\subsection{FTIR spectroscopy}

Infrared spectra are measured by a Varian 660 FTIR spectrometer controlled by Resolution software. Samples are mixed with dry $\mathrm{KBr}$ in the ratio of 4:200 and measured for 16 scans in transmission mode over the range $4,000-400 \mathrm{~cm}^{-1}$.

\subsection{X-ray fluorescence (XRF) and diffraction (XRD)}

XRF measurements are made using PANalytical MiniPal4 at the Rutherford Appleton Laboratory in the UK, and the XRD data are also collected at the same laboratory, using a PANalytical X'pert Pro diffractometer. The XRD diffractometer is optimised for studying the structure of amorphous materials by mounting the samples in capillaries and using a silver anode tube to produce the X-rays. The powdered samples are enclosed in a $1 \mathrm{~mm}$ diameter tube; this allows

data to be collected over a wide angular range with a $Q_{\max }$ up to $\sim 20 \AA^{-1}$ where $Q=4 \pi \sin \theta / \lambda$. Other XRD data are collected on beamline MCX in the Elettra 
synchrotron, Italy, where the powdered samples are enclosed in a $0.7 \mathrm{~mm}$ diameter silica capillary.

The raw X-ray data is then analysed to convert to the interference function $i(Q)$. The resulting scattering intensity, $i(Q)$, exposes structural information via a Fourier transform (FT) to obtain the total correlation function, as given in Equation (1):

$$
T_{X}(r)=2 \pi^{2} \rho r+\int_{Q_{\min }}^{Q_{\max }} M(Q) \cdot Q \cdot i_{X}(Q) \cdot \sin (Q r) \cdot d Q \quad \text { Equation (1) }
$$

where $r$ is the atomic separation, $\rho$ is the density and $M(Q)$ is the applied modification function to reduce the FT termination artefacts which arise from the finite range of $Q$. The Lorch modification function is used in this work.

In order to obtain some information about the structure from the real space correlation function, it is essential that the correlation functions, $p_{i j}(r)$ are modelled using equation (2)

$$
p_{i j}(Q)=\frac{N_{i j} \omega_{i j} \sin Q R_{i j} \exp \left(-0.5 Q^{2} \sigma_{i j}^{2}\right)}{c_{j} Q R_{i j}}
$$

where $N_{i j}, R_{i j}$ and $\sigma_{i j}$ are the coordination number, atomic separation and disorder parameter of atom type $i$ in relation to atom type $j$, respectively. The parameter $c_{j}$ refers to the concentration of atom $j$. The weighting factor $\omega_{i j}$ is then given by Equation (3):

$$
\omega_{i j}=\frac{\left(2-\delta_{i j}\right) c_{i} c_{j} f_{i}(Q) f_{j}(Q)}{[\overline{f(Q)}]^{2}}
$$


where $f_{i}(Q)$ refer to the variation in scattering strength of different atom types. The $p_{i j}(Q)$ values are demonstrated in $Q$-space using Equation (2), then summed and Fourier transformed using Equation (1). They are subjected to the same Fourier effects as the experimental data. The sum of $p_{i j}(Q)$ is similar to the $i_{X}(Q)$ in Equation (1). Finally, the NXfit program [24] is used to obtain the information on the structure from the experimental data.

\subsection{Neutron diffraction (ND)}

SANDALS instrument at target station 1 on the ISIS spallation neutron source at the Rutherford Appleton Laboratory, UK has been used to collect the neutron diffraction data. Time-of-flight data is composed over a wide range of $Q$ (up to $40 \mathrm{~A}^{-1}$ ). The sample can is a TiZr container, $4 \mathrm{~mm}$ thick $\mathrm{x} 34 \mathrm{~mm}$ wide $\mathrm{x} 37.5 \mathrm{~mm}$ high. The mixture of $70 \%$ titanium with $30 \%$ zirconium provides a 'null scatterer' as the coherent scattering is zero. A sequence of modifications [23] is made to the raw data using the GUDRUN program [23]. In addition, the ND data is adjusted for the magnetic scattering, which is increased with increasing the extent of Fe (see Figure 5).

Although the principles behind neutron diffraction are similar to those for Xrays, the differences arise because X-rays scatter from the electron clouds while neutrons scatter from nuclei. The entire correlation function for ND is given by Equation (4):

$$
T_{N}(r)=4 \pi \rho_{N} r\left(\sum_{i} c_{i} b_{i}\right)^{2}+\frac{2}{\pi} \int_{Q_{\min }}^{Q_{\max }} M(Q) \cdot Q \cdot i_{N}(Q) \cdot \sin (Q r) \cdot d Q \quad \text { Equation (4) }
$$

Here, $b_{i}$ refers to the scattering length. As in XRD, the Lorch function is also used here. Equation (5) demonstrates a pair correlation function of any atom pair and $\omega_{i j}$ is given by: 


$$
\omega_{i j}=\left(2-\delta_{i j}\right) c_{i} c_{j} b_{i} b_{j}
$$

Equation (5)

Again, the NXfit program [24] is employed to obtain information about the structure directly from the experimental data.

\subsection{X-ray absorption spectroscopy}

The EXAFS and XANES data are collected using the facilities on beamlines X1 and A1 at the DORIS Synchrotron at Hasylab in Germany. (The EXAFS and XANES measurements were first made using the X1 beam line. Later they were made using the A1 beam line in order to improve energy resolution, but only a modest improvement was achieved.) Data are collected around the $\mathrm{Fe} \mathrm{K}$ edge at $7111 \mathrm{eV}$. The fine-milled powder is diluted with polyvinyl pyrrolidone (PVP) and compacted into pellets of $13 \mathrm{~mm}$ diameter. Three ionisation chambers are used to record the incident, transmitted and calibrated beam intensities in a double crystal $\mathrm{Si}(111)$ monochromator. A $5 \mu \mathrm{m}$ Fe foil is located between the second and third chambers in which the foil absorption spectrum is recorded simultaneously with the sample spectrum. In order to analyse the data, XANDA, VIPER and EXCURV98 programs are used. The $k^{3}$-weighted EXAFS signal $\chi(\mathrm{k})$ is fitted to achieve standards for structural parameters containing $N, R$ and the Debye-Waller factor, $A=2 \sigma^{2}$. Fitting of the EXAFS spectrum is restricted between $k=2.5$ and $12.5 \mathrm{~A}^{-1}$. The EXAFS oscillations $\chi(\mathrm{k})$ are given by:

$$
\begin{aligned}
& \chi(k)=S_{0}(k)^{2} \sum_{j} \frac{N_{j}}{k R_{j}^{2}}\left|f\left(\pi, k, R_{j}\right)\right| e^{-2 R_{j} / \lambda(k)} e^{-2 \sigma_{j}^{2} k^{2}} \\
& \times \sin \left(2 k R_{j}+2 \delta(k)+\psi\left(k, R_{j}\right)\right)
\end{aligned}
$$


where $k, f\left(\pi, k, R_{j}\right)$ and $\lambda(k)$ are the photoelectron wavevector, backscattering and mean free path, respectively. $\delta(k)$ and $\psi\left(k, R_{j}\right)$ are the phase shifts experienced by the photoelectron at the central and neighbouring atoms, respectively. The term $S_{o}(k)^{2}$ refers to the decrease in amplitude due to many body effects. $\left(S_{o}(k)^{2}=1\right.$ when neglecting these effects). This factor is known as AFAC. It is only measured experimentally using crystalline standards of reference samples. The magnitude of AFAC is found $=0.8$ by fitting the data of $\alpha-\mathrm{Fe}_{2} \mathrm{O}_{3}, \gamma-\mathrm{Fe}_{2} \mathrm{O}_{3}$ and $\mathrm{Fe}_{3} \mathrm{O}_{4}$. Equation (7) introduces a non-linear least squares fit in $k$ space with a $k^{3}$ weighting to minimise the fit index (FI) in order to obtain the samples' structural features.

$$
F I=\sum_{i}\left(k^{3}\left(\chi_{i}^{T}-\chi_{i}^{E}\right)\right)^{2}
$$

where $\chi_{i}^{\mathrm{T}}$ and $\chi_{\mathrm{i}}^{\mathrm{E}}$ are the theoretical and experimental EXAFS, respectively. Fitting quality is adjudged from the discrepancy index $\left(R_{E X A F S}\right)$ as in Equation (8). An acceptable value of $\mathrm{R}_{\mathrm{EXAFS}}$ is between $20 \%$ and $40 \%$.

$$
R_{\text {EXAFS }}=\frac{\sum_{i=1}^{N} k^{3}\left|\chi_{i}^{\exp }(k)-\chi_{i}^{\text {theory }}(k)\right|}{\sum_{j=1}^{N} k^{3}\left|\chi_{j}^{\exp }(k)\right|} \times 100 \%
$$




\section{Results}

\subsection{FTIR spectroscopy}

Fourier-transform infrared spectroscopy (FTIR) spectra of the samples in the frequency range of $400-1,600 \mathrm{~cm}^{-1}$ are shown in Figure 1. They consist of a number of overlapping bands that are typical of FTIR spectra from phosphate glasses, and the band locations are tabulated in Table 2. The structures of the phosphate glasses are well known to consist of $\mathrm{PO}_{4}$ tetrahedral units connected by bridging oxygens to form the network [3]. The bands in the range of 480$530 \mathrm{~cm}^{-1}$ are assigned to the $\mathrm{FeO}_{4}, \mathrm{FeO}_{6}$ and bending harmonics of O-P-O groups [21], and the intensity of these bands is constant with increasing iron oxide. The $700-780 \mathrm{~cm}^{-1}$ band is ascribed to the symmetric stretching modes of the P-O-P linkages [25]. The bands at $900-941 \mathrm{~cm}^{-1}$ and $960 \mathrm{~cm}^{-1}$ are due to P-O-P asymmetric bond stretching and isolated $\mathrm{PO}_{4}$ respectively [26]. Their intensities shift to higher wavenumbers and the amplitudes increase with adding more $\mathrm{Fe}_{2} \mathrm{O}_{3}$ content, indicating an increase in $Q^{0}$ units replacing $Q^{l}$ and $Q^{2}$. The shift to higher wavenumbers shows that the chain length is shorter for the Fe-rich samples due to the depolymerisation of the glass structure [27, 28].

The band in the range of 1,078 to $1,178 \mathrm{~cm}^{-1}$ is assigned to the ionic groups of $\mathrm{P}$ $\mathrm{O}^{-}[29,30]$, and its amplitude is constant with increasing the $\mathrm{Fe}$ content. The band near $1,074 \mathrm{~cm}^{-1}$ is found to be shifted to a higher frequency and its intensity increases with increasing $\mathrm{Fe}_{2} \mathrm{O}_{3}$ content, suggesting that the $\mathrm{Fe}-\mathrm{O}-\mathrm{P}$ bonds would form and replace the $\mathrm{P}_{-} \mathrm{O}^{-}$and $\mathrm{P}-\mathrm{O}-\mathrm{P}$ bonds [31]. A strong band near 1,245$1,282 \mathrm{~cm}^{-1}$ is given to asymmetric stretching modes of the two NBO atoms bonded to phosphorus atoms $\left(\mathrm{PO}_{2}\right)$, or $Q^{2}$ units in the phosphate tetrahedra [27, 
29, 32]. Its amplitude decreased with increasing $\mathrm{Fe}_{2} \mathrm{O}_{3}$ and it disappeared in the sample with $40 \% \mathrm{Fe}_{2} \mathrm{O}_{3}$. This confirms that the phosphate chains are shortened as the Fe ions are incorporated into the glass network and $Q^{2}$ units [29] are replaced by $Q^{1}$ and $Q^{0}$.

\subsection{X-ray fluorescence}

XRF spectroscopy shows several transitions (Figure 2) which help with determination of the chemical composition of the materials under investigation. The obvious transitions are $\mathrm{P} \mathrm{K}_{\alpha}$ and $\mathrm{Fe} \mathrm{K}_{\alpha}$ at $2.01 \mathrm{KeV}$ and $6.4 \mathrm{KeV}$ respectively. (The XRF spectrum does not show $\mathrm{Na}$ because the measurements were made in air.) The smaller peak at $7.08 \mathrm{KeV}$ comes from $\mathrm{Fe} \mathrm{K}_{\beta}$ transition. Figure 3 compares the $\mathrm{Fe} / \mathrm{P}$ ratio in glasses calculated theoretically with the XRF experimental measurements. The straight line is an indication of the accurate determination of the composition of the samples.

\subsection{X-ray and neutron diffraction measurements}

The experimental ND and XRD interference functions $i(Q)$ are presented in Figure 4. The dashed lines in XRD data are the results from the Elettra synchrotron, Italy. Hannon [33, 34] developed a method to correct the magnetic scattering for ND data. Figure 5 presents the FTs of neutron and X-ray diffraction $i(Q)$. The maximum $Q$ values used in the FT of the X-ray data are $20 \AA^{-1}$ for $10 \mathrm{Fe}$ and $20 \mathrm{Fe}$, and a value of $18.5 \AA^{-1}$ has been chosen as $Q_{\max }$ in the 30Fe sample, and $40 \AA^{-1}$ was used for neutron $i(Q)$ for all samples. (The $40 \mathrm{Fe}$ sample was not studied using XRD because the high Fe content caused too much absorption, and was not studied using ND because the amount of glass produced 
by melt quenching was too small.) Due to the overlapping correlations at $\mathrm{R} \sim 3.5$ $\AA$, the fitting of the data is restricted to correlations up to $\sim 3.5 \AA$. A reasonable fit of an individual pair correlation depends on the contribution of other correlations at the distance at which it is located. Therefore, it is essential to use two or three peaks after the last correlation to act as 'background', which do not essentially yield a real feature [24]. The XRD and ND data are separately fitted with the same order of interatomic correlations as discussed below. However, the high $Q$ value for neutron diffraction data helped to clarify the P-O peak into contributions from $\mathrm{P}-\mathrm{O}_{\mathrm{nb}}$ and $\mathrm{P}-\mathrm{O}_{\mathrm{b}}$. The optimised structural parameters values gained from fitting XRD and ND data are tabulated in Table 3.

The first common feature characterising both ND and the XRD data in phosphate glasses is the $\mathrm{P}-\mathrm{O}$ interatomic correlation at $\sim 1.54 \AA$. The second correlation is the Fe-O for which the coordination number appears to decrease with increasing $\mathrm{Fe}_{2} \mathrm{O}_{3}$. This distance is attributed to $\mathrm{Fe}^{3+}$ rather than $\mathrm{Fe}^{2+}$ (as discussed in XANES results). The shorter Fe-O bond distances are consistent with the smaller coordination number in the direction of increasing $\mathrm{Fe}_{2} \mathrm{O}_{3}$ content. It was difficult to fit $\mathrm{Fe}^{2+}-\mathrm{O}$ accurately, however, missing this peak will slightly alter $\mathrm{Fe}^{3+}$ and $\mathrm{Na}^{1+}$ correlations. The next correlation to be fitted is $\mathrm{Na}-\mathrm{O}$ at $2.3 \AA$ for the first coordination shell. However, this peak appears as a broad shoulder at the low side of the $\mathrm{O}-\mathrm{O}$ peak. The average $\mathrm{Na}-\mathrm{O}$ interatomic distance and the average coordination number are in agreement with the experimental results of $\mathrm{R}=2.38 \AA$ and $\mathrm{N}=5$ obtained by Hoppe et al. [35] using XRD and ND for the sodium phosphate glasses. The region from 2.5 to $\sim 2.9 \AA$ is dominated by the O-O interatomic correlation. The first O-O peak at $2.5 \AA$ is attributed to O-P-O distance while the second peak originates from $\mathrm{O}-\mathrm{Fe}-\mathrm{O}$. There is a narrow peak 
at $2.9 \AA$ representing P-P nearest neighbours in the phosphate network. The $10 \mathrm{Fe}$ sample has $[\mathrm{O}] /[\mathrm{P}]=3$; this means that each $\mathrm{P}$ atom is probably coordinated by four $\mathrm{O}$ atoms in $Q^{2}$ units. This is confirmed through the P-P coordination number $\sim 2$ as expected with the interatomic distance of $\sim 2.9 \AA$, while the P-P coordination number is 1.5 in the $30 \mathrm{Fe}$ sample because the $\mathrm{O} / \mathrm{P}$ ratio is increased to 3.33. Although the Fe-P interatomic distance acts as a background, it is expected to be at $3.2 \AA$, however, the coordination number cannot be accepted as reliable because of the overlapping of this peak with other peaks, such as $\mathrm{Fe}-\mathrm{Na}$ distance, which is reported to be close to this distance as well [18]. Note that for the 40Fe composition, the XRD data outlined in Table 3 is obtained by Karabulut et al. [36] and ND data by Wright et al. [9].

\subsection{X-ray absorption measurements (XANES)}

Iron is naturally found in four to six-fold coordination surroundings. Figures 6 and 7 present the XANES spectra for all samples with the reference samples from beamlines X1 and A1, respectively. The target atom's oxidation state and its local surroundings are determined by the shape and position of the edge through the comparison with well-known standard crystal structures. The sequence of the main edge position, which is closer to $\mathrm{Fe}_{2} \mathrm{O}_{3}$ than $\mathrm{Fe}_{3} \mathrm{O}_{4}$, indicates that the samples under investigation have mostly $\mathrm{Fe}^{3+}$ with a small amount of $\mathrm{Fe}^{2+}$ (less than 25\%). This is reasonably consistent with the results of Mossbauer spectroscopy for sodium iron phosphate glasses with quite similar compositions that indicated $12-20 \% \mathrm{Fe}^{2+}[13]$. A Mossbauer study of $40 \mathrm{Fe}_{2} \mathrm{O}_{3}-$ $60 \mathrm{P}_{2} \mathrm{O}_{5}$ glasses with additions of up to $10 \mathrm{~mol} \%$ of both $\mathrm{UO}_{2}$ and $\mathrm{Na}_{2} \mathrm{O}$ together showed $11-16 \%$ of $\mathrm{Fe}^{2+}$ [37]. In addition, it is clear that the environment of iron 
in all glasses is similar but not identical because the pre-edge peak at approximately $7,113 \mathrm{eV}$ increases in intensity as iron content increases. It is well known that the intensity of the pre-edge peak increases when iron changes coordination from octahedral to tetrahedral [38]. The inset in these figures highlights the pre-edge region which confirms that the coordination number of iron decreases with increasing iron content. Hence, the XANES results are clear evidence that iron coordination is less than 6 and decreases toward 5 as iron content increases.

\subsection{EXAFS}

Figures 8 and 10 show the EXAFS spectra for the four samples with associated fitting in $k$ space from beamlines $\mathrm{X} 1$ and $\mathrm{A} 1$ respectively. Their corresponding FTs are shown in Figures 9 and 11. The accuracy of coordination numbers, N, from the EXAFS fitting is limited because of the correlation with the DebyeWaller (DW) factor, $A$. Therefore, one of them needs to be fixed to typical values reported from the literature. In the present fitting, all of the parameters have been allowed to vary first until the reasonable DW factor has been found which gave a realistic value for $\mathrm{N}$ and $\mathrm{R}$. EXAFS results are reasonably established to be precise to $\pm 0.02 \AA$ for $\mathrm{R}$. However, $\mathrm{N}$ is only exact to $\pm 20 \%$. An AFAC value of 0.8 is found by fitting the data for crystal $\mathrm{FeO}$, alpha $\mathrm{Fe}_{2} \mathrm{O}_{3}$, gamma $\mathrm{Fe}_{2} \mathrm{O}_{3}$ and $\mathrm{Fe}_{3} \mathrm{O}_{4}$. Two shells have been fitted: $\mathrm{Fe}-\mathrm{O}$ at approximately $2 \AA$ and $\mathrm{Fe}-\mathrm{P}$ at approximately $3.2 \AA$. Although there is an overlapping correlation at $3.2 \AA$ between Fe-Na and Fe-P shells, only one shell could sensibly be fitted independently and Fe-P has been chosen as the highest backscattering contribution. In fact, the possible overlap with Fe-Na correlation increased the 
uncertainty in the fitted Fe-P shell in addition to the usual difficulty in getting a reasonable value for the coordination number of fitting the second shell in EXAFS data from glasses due to structural disorder. Table 4 summarises the results from fitting EXAFS data from beamlines X1 and A1. An additional shell referring to Fe-Fe correlation could be fitted in the $40 \mathrm{Fe}$ sample at $\sim 3.5 \AA$. From Table 3 and Figures 9 and 11 it can be concluded that the Fe-O peak shifted to smaller R with increasing iron oxide content as well as the coordination number of Fe-O getting lower. The lower values of $\mathrm{Fe}-\mathrm{O}$ coordination numbers observed in the data obtained from beamline A1 could be attributed to the presence of a nickel mirror which is used to focus the X-ray beam.

\section{Discussion}

As expected, phosphorus is coordinated to four oxygen atoms. In fitting the neutron diffraction data there was a possibility of further resolving the P-O peak using the full range of the ND data into the contributions from $\mathrm{P}-\mathrm{O}_{\mathrm{nb}}$ at $\sim 1.50 \AA$ and $\mathrm{P}-\mathrm{O}_{\mathrm{b}}$ at $\sim 1.58 \AA$. These interatomic distances matched well with the previous studies of metaphosphate and pyrophosphate glasses [39]. The results in Table 3 are in agreement with Hoppe et al.'s [20] observation that both $\mathrm{P}-\mathrm{O}_{\mathrm{nb}}$ and $\mathrm{P}-\mathrm{O}$ bond distances become larger as the metal cation concentration increases. However, the average P-O distance remains the same over a broad range of composition. This is also noticed for the $\mathrm{Si}-\mathrm{O}$ distance in sodium iron silicate glasses [40].

Phosphorus is coordinated to four $\mathrm{O}$ atoms in tetrahedral arrangement. On average, each $\mathrm{O}$ atom is surrounded by four others at a distance of $\sim 2.52 \AA$. Using an average P-O distance of $1.54 \AA$, the average O-P-O bond angle is 
calculated at $110^{\circ}$ which confirms the tetrahedral environment. The $[\mathrm{O}] /[\mathrm{P}]$ ratio is a vital parameter to track the glass structural changes. The main part of the presented ND and XRD results contribute to the knowledge of the environment of the Fe modifier in the glasses. This is the most prominent peak in the XRD and neutron $T(r)$. The Fe-O coordination numbers decreased with increasing mixed iron oxide. This trend was observed by Hoppe et al. [39] and Wright et al. [9] in their articles on iron phosphate glasses. The effect of metal concentration on metal cation coordination number was investigated by Hoppe and his colleagues. They proposed that at low metal cation content, the metal cation coordination is high because the ratio of the number of non-bridging oxygen atoms, $\mathrm{O}_{\mathrm{nb}}$, plus terminal oxygens, $\mathrm{O}_{\mathrm{T}}$, to the number of metal cations is relatively high. However, this ratio is reduced when the metal cation concentration increases, therefore the metal coordination number decreases. A minimum metal cation coordination number is obtained when adding more metal cation content. After this has happened, the metal-oxygen polyhedra begin to share edges and corners. Then the metal cation coordination increases and presents a more compact structure. It is logical to assume that the amount of $\mathrm{Na}^{+}$ has a slighter effect on the structure compared with $\mathrm{Fe}^{3+}$ because the latter creates more NBO.

Generally speaking, $\mathrm{Fe}^{3+}$ plays the key role in adapting the properties of phosphate glasses through strengthening the cross-bonding of the phosphate matrices. The XANES results indicate one quarter of $\mathrm{Fe}$ is present as $\mathrm{Fe}^{2+}$ based on the position of the absorption edge (the so-called "half height" method), and this is consistent with Mossbauer studies of similar glasses [6, 37]. The same "half height" method was used in a Fe K-edge XANES study of $31 \mathrm{Fe}_{3} \mathrm{O}_{4}-69 \mathrm{P}_{2} \mathrm{O}_{5}$ 
glasses with up to $15 \mathrm{~mol} \% \mathrm{Na}_{2} \mathrm{O}$ added [41], and showed a amount of $25-30 \%$ $\mathrm{Fe}^{2+}$ (which is higher due to the $\mathrm{Fe}_{3} \mathrm{O}_{4}$ reactant and a higher $\mathrm{P}_{2} \mathrm{O}_{5}$ content). The same study [41] analysed the Fe K-edge pre-edge peak by fitting a minor contribution (at $7112.4 \mathrm{eV}$ ) due to $\mathrm{Fe}^{2+}$, and a dominant contribution (at 7114.5 $\mathrm{eV}$ ) due to $\mathrm{Fe}^{3+}$ with a significant amount of $\mathrm{Fe}^{3+}$ having coordination number below 6 . The same peak fitting analysis of the pre-edge peak was used in a study of $40 \mathrm{Fe}_{2} \mathrm{O}_{3}-60 \mathrm{P}_{2} \mathrm{O}_{5}$ glasses with additions of up to $10 \mathrm{~mol} \%$ of both $\mathrm{UO}_{2}$ and $\mathrm{Na}_{2} \mathrm{O}$ together [37] and also showed a dominant contribution due to $\mathrm{Fe}^{3+}$ with a significant amount of $\mathrm{Fe}^{3+}$ having coordination number below 6 . The above studies reporting qualitative results from fitting of pre-edge peaks were possible due to using the SSRL beamline 4-1 with superior energy resolution. (The lower energy resolution of the XANES data in the present study would make fitting of pre-edge peaks inaccurate.)

EXAFS provides quantitative results concerning the $\mathrm{Fe}-\mathrm{O}$ coordination number. The present study shows a clear increase in from below 5 for $40 \mathrm{Fe}_{2} \mathrm{O}_{3}-60 \mathrm{P}_{2} \mathrm{O}_{5}$ glass to 5.7 for $30 \mathrm{Na}_{2} \mathrm{O}-10 \mathrm{Fe}_{2} \mathrm{O}_{3}-60 \mathrm{P}_{2} \mathrm{O}_{5}$ glass. EXAFS studies in the literature have shown similar results. EXAFS showed an Fe-O coordination number of 4.8 in a $31 \mathrm{Fe}_{2} \mathrm{O}_{3}-69 \mathrm{P}_{2} \mathrm{O}_{5}$ glass, which increases with addition of up to $15 \mathrm{~mol} \% \mathrm{Na}$ [41]. EXAFS showed and $\mathrm{Fe}-\mathrm{O}$ coordination number of 5.2 in as $5 \mathrm{UO}_{2}-5 \mathrm{Na}_{2} \mathrm{O}-$ $36 \mathrm{Fe}_{2} \mathrm{O}_{3}-54 \mathrm{P}_{2} \mathrm{O}_{5}$ glass, which increased to 5.6 in a $10 \mathrm{UO}_{2}-10 \mathrm{Na}_{2} \mathrm{O}-32 \mathrm{Fe}_{2} \mathrm{O}_{3}-$ $48 \mathrm{PP}_{2} \mathrm{O}_{5}$ glass [37].

The diffraction results presented here agree with the EXAFS data as the Fe-O coordination number decreases from $~ 5.7$ to 4.5 . Wright et al. [9], in their ND study of $40 \mathrm{Fe}_{2} \mathrm{O}_{3}-60 \mathrm{P}_{2} \mathrm{O}_{5}$ glass, found that the $\mathrm{Fe}^{3+}-\mathrm{O}$ coordination number is 5 with bond distance $1.94 \AA$. Similar results were obtained in their follow on study 
[42] of iron phosphate glasses with a wider composition range of 30-44mol\% $\mathrm{Fe}_{2} \mathrm{O}_{3}$. Bingham and Barney [43] made a combined XRD and ND study of alkali iron phosphate glasses $\mathrm{xK}_{2} \mathrm{O}(1-\mathrm{x})\left(40 \mathrm{Fe}_{2} \mathrm{O}_{3}-60 \mathrm{P}_{2} \mathrm{O}_{5}\right)$ with $\mathrm{x}=0-0.4$. They found $15-26 \% \mathrm{Fe}^{2+}$ and $\mathrm{Fe}-\mathrm{O}$ coordination numbers of 5.2-5.4 (note that differently to the present study, their samples had $\mathrm{K}$ instead of $\mathrm{Na}$, and the $\mathrm{P}_{2} \mathrm{O}_{5}$ content decreased to $36 \mathrm{~mol} \%$ instead of staying constant at $60 \mathrm{~mol} \%$ ).

The second type of cation-oxygen bond is Na-O correlation. Table 3 shows that each sodium atom is coordinated by $\sim 5$ oxygen atoms with a typical distance of $\sim 2.34 \AA$. There is a clear difference between Na-O distances from ND and XRD data, and the difference increases as $\mathrm{Na}_{2} \mathrm{O}$ content decreases. This is because $\mathrm{Fe}$ $\mathrm{O}$ and $\mathrm{O}-\mathrm{O}$ distances heavily overlap with $\mathrm{Na}-\mathrm{O}$ distances. The most accurate results were obtained for the highest $\mathrm{Na}_{2} \mathrm{O}$ content which is in the $10 \mathrm{Fe}$ sample. This gives an Na-O distance of $2.33 \AA$. The relation of Na-O bond lengths and the calculated bond valence is determined by the Brese and O'Keeffe relation [44] as given in Equation (9):

$v_{N a-O}=\exp \left[\frac{r_{N a-O}-R_{N a-O} \AA}{0.37 \AA}\right]$

Equation (9)

where $\mathrm{r}_{\mathrm{Na}-\mathrm{O}}=1.80 \AA$ is the bond valence parameter. The factor of $0.37 \AA$ is an empirical derived constant. Applying this to the diffraction results as each sodium atom is coordinated by five oxygen atoms with a mean separation of 2.33 $\AA$ and the calculated bond valence is $v_{N a-O}=0.24$, which corresponds well with the bond valence of $\mathrm{Na}^{1+}$ ion.

\section{Conclusion}


A complete atomic structure study of a series of Na-Fe phosphate glasses is concluded using several experimental techniques, complementary $\mathrm{X}$-ray and neutron diffraction, IR, EXAFS and XANES. The high resolution of neutron diffraction in real space resolves two $\mathrm{P}-\mathrm{O}_{\mathrm{nb}}$ and $\mathrm{P}-\mathrm{O}_{\mathrm{b}}$ distances at $\sim 1.50 \AA$ and $1.58 \AA$ as expected. The glass networks vary from metaphosphate to pyrophosphate as iron content increases from 10 to $40 \% \mathrm{Fe}_{2} \mathrm{O}_{3}$. The addition of either $\mathrm{Na}$ or $\mathrm{Fe}$ has an effect on the intermediate range order of phosphate structure. Each phosphate unit has two or three NBO atoms available to coordinate with $\mathrm{Na}$ and $\mathrm{Fe}$ cations. The $\mathrm{Na}-\mathrm{O}$ correlation is recognised at $\mathrm{R} \sim$ $2.34 \AA$ with $\mathrm{N}_{\mathrm{Na}-\mathrm{O}} \sim 5$. XANES confirms that $\mathrm{Fe}$ is found to occur mainly as $\mathrm{Fe}^{3+}$ in all the glasses. As expected, the addition of iron oxide decreased the connectivity, however, the coordination of the iron by NBO atoms is also decreased. The XRD, ND, XANES and EXAFS results all indicate a clear trend of reducing the $\mathrm{Fe}-\mathrm{O}$ coordination number from $\sim 5.7$ to 4.5 as iron content increases from 10 to $40 \% \mathrm{Fe}_{2} \mathrm{O}_{3}$.

\section{References}

1. Musinu A, Piccaluga G, Pinna G. Structural properties of lead iron phosphate glasses by X-ray diffraction. J Non Cryst Solids. 1990;122(1):52-58.

2. Greaves GN, Gurman SJ, Gladden LF, et al. A structural basis for the corrosion resistance of lead iron phosphate glasses - an X-ray absorption spectroscopy study. Philos Mag B-Physics Condens Matter Stat Mech Electron Opt Magn Prop. 1988;58(3):271-283. 
3. Brow R. The structure of simple phosphate glasses, J Non Cryst Solids. $2000 ; 263-264: 1-28$.

4. Sales BC, Boatner LA. Lead iron phosphate glass - a stable storage medium for high level nuclear waste. Science (80- ). 1984;226(4670):45-48.

5. Sales BC, Boatner LA. Physical and chemical characteristics of lead iron phosphate nuclear waste glasses. J Non Cryst Solids. 1986;79(1-2):83-116.

6. Yu XY, Day DE, Long GJ, Brow RK. Properties and structure of sodiumiron phosphate glasses. J Non Cryst Solids. 1997;215(1):21-31.

7. Pegg I, Joseph I. Vitrification. In: Chang, H, ed. Hazardous and Radioactive Waste Treatment Technologies Handbook. Boca Raton: CRC Press, 2001; ch. 4.2.8. Bingham PA, Forder SD, Hand RJ, Lavaysierre A. Mossbauer studies of phosphate glasses for the immobilisation of toxic and nuclear wastes. Hyperfine Interact. 2005;165(1-4):135-140.

9. Wright AC, Sinclair RN, Shaw JL, Haworth R, Marasinghe GK, Day DE. A neutron diffraction study of the structure of iron phosphate glasses. Phys Chem Glas J Glas Sci Technol Part B. 2008;49(1):1-7.

10. Kurkjian CR. Mechanical properties of phosphate glasses. J Non Cryst Solids. 2000;263(1-4):207-212.

11. Moustafa YK. Effect of iron chloride on the polaronic conduction in potassium phosphate glasses containing iron oxide. Can $J$ Phys. 2000;78(12):1091-1105.

12. Doweidar H, Eldamrawi GM, Moustafa YM. Transport properties of semiconducting $\mathrm{Fe} 2 \mathrm{O} 3-\mathrm{PbO}-\mathrm{B} 2 \mathrm{O} 3$ glasses. $J$ Physics-Condensed Matter. 1994;6(42):8829-8838. 
13. Mogus-Milankovic A, Gajovic A, Santic A, Day DE. Structure of sodium phosphate glasses containing $\mathrm{Al}_{2} \mathrm{O}_{3}$ and/or $\mathrm{Fe}_{2} \mathrm{O}_{3}$. Part I. J Non Cryst Solids. 2001;289(1-3):204-213.

14. Jantzen CM. Systems approach to nuclear waste glass development. $J$ Non Cryst Solids. 1986;84(1-3):215-225.

15. Donald IW, Metcalfe BL, Taylor RNJ. The immobilization of high level radioactive wastes using ceramics and glasses. J Mater Sci. 1997;32(22):58515887.

16. Bingham PA, Hand RJ, Hannant OM, Forder SD, Kilcoyne SH. Effects of modifier additions on the thermal properties, chemical durability, oxidation state and structure of iron phosphate glasses. J Non Cryst Solids. 2009;355(2830):1526-1538.

17. Parsons AJ, Rudd CD. Glass forming region and physical properties in the system $\mathrm{P}_{2} \mathrm{O}_{5}-\mathrm{Na}_{2} \mathrm{O}-\mathrm{Fe}_{2} \mathrm{O}_{3}$. J Non Cryst Solids. 2008;354(40-41):4661-4667.

18. Musinu A, Piccaluga G, Pinna G. X-ray diffraction investigation of iron in sodium phosphate glasses. J Phys Chem. 1996;100(30):12462-12466.

19. Hoppe U, Walter G, Kranold R, Barz A, Stachel D, Hannon AC. A diffraction study of the structure of vitreous $\mathrm{P}_{2} \mathrm{O}_{5}$. Glastechnische Berichte. 1998;71C:192-197.

20. Hoppe U, Walter G, Kranold R, Stachel D. X-ray diffraction study of the structure of vitreous $\mathrm{P}_{2} \mathrm{O}_{5}$. Zeitschrift Fur Naturforsch Sect A. 1998;53(3-4):93104.

21. Wang G, Wang Y, Jin B. Structural properties of sodium-iron phosphate glasses. In: Marker, AJ, ed. Proceedings of SPIE 2287, Properties and 
Characteristics of Optical Glass III; 1994 24-29 July; San Diego, United States. 1994. p. 214-225.

22. Yu X, Day DE. Effect of raw materials on the redox state of iron and properties of iron phosphate glasses. In: Fangtian G, ed. Proceedings of the 17th International Congress on Glass. 1995 9-14 Oct; Beijing, China. Beijing: International Academic Publishers; 1995. Vol. 2 p. 45.

23. Soper AK, Gudrun N, Gudrun X. Programs for correcting raw neutron and X-ray diffraction data to differential scattering cross section. Harwell: Science and Technology Facilities Council; 2011. Technical Report RAL-TR2011-013.

24. Moss R. Structural studies of metal doped phosphate glasses and computational developments in diffraction analysis [unpublished $\mathrm{PhD}$ thesis]. Canterbury (UK): University of Kent; 2009.

25. Byun JO, Kim BH, Hong KS, Jung HJ, Lee SW, Izyneev AA. Properties and structure of RO-Na $\mathrm{O}_{2}-\mathrm{Al}_{2} \mathrm{O}_{3}-\mathrm{P}_{2} \mathrm{O}_{5}(\mathrm{R}=\mathrm{Mg}, \mathrm{Ca}, \mathrm{Sr}, \mathrm{Ba})$ Glasses. J Non Cryst Solids. 1995;190(3):288-295.

26. Liu HS, Chin TS, Yung SW. FTIR and XPS studies of low-melting PbOZnO- $\mathrm{P}_{2} \mathrm{O}_{5}$ glasses. Mater Chem Phys. 1997;50(1):1-10.

27. Shih PY. Properties and FTIR spectra of lead phosphate glasses for nuclear waste immobilization. Mater Chem Phys. 2003;80(1):299-304.

28. Shih PY, Chin TS. Effect of redox state of copper on the properties of $\mathrm{P}_{2} \mathrm{O}_{5}-\mathrm{Na}_{2} \mathrm{O}-\mathrm{CuO}$ glasses. Mater Chem Phys. 1999;60(1):50-57.

29. Brow RK, Tallant DR, Myers ST, Phifer CC. The short-range structure of zinc polyphosphate glass. J Non Cryst Solids. 1995;191(1-2):45-55. 
30. Bartholomew R. Structure and properties of silver phosphate glasses Infrared and visible spectra. J Non Cryst Solids. 1972; 7(3):221-235.

31. Mogus-Milankovic A, Pivac B, Furic K, Day DE. Structural study of iron phosphate glasses. Phys Chem Glas. 1997;38(2):74-78.

32. Hudgens JJ, Martin SW. Glass transition and infrared spectra of low alkali, anhydous lithium phosphate glasses. J Am Ceram Soc. 1993;76(7):16911696.

33. Hannon AC. 2010, Private communication.

34. Brown P. In: Wilson AJC, ed. International tables for crystallography, Vol. C. Dordrecht: Kluwer, 1995;454-461.

35. Hoppe U, Stachel D, Beyer D. The oxygen coordination of metal ions in phsophate and silicate glasses studied by a combination of X-ray and neutron diffraction. Phys Scr. 1995;T57:122-126.

36. Karabulut M, Marasinghe GK, Ray CS, et al. A high energy X-ray and neutron scattering study of iron phosphate glasses containing uranium. J Appl Phys. 2000;87(5):2185-2193.

37. Karabulut M, Marasinghe GK, Ray CS, et al. Local environment of iron and uranium ions in vitrified iron phosphate glasses studied by FeK and U L-III-edge X-ra y absorption fine structure spectroscopy. J Mater Res. 2000;15(9): 19721984.

38. Yano J, Yachandra VK. X-ray absorption spectroscopy. Photosynth Res. 2009;102(2-3):241-254. 
39. Hoppe U, Karabulut M, Metwalli E, Brow RK, Jovari P. The Fe-O coordination in iron phosphate glasses by X-ray diffraction with high energy photons. J Physics-Condensed Matter. 2003;15(36):6143-6153.

40. Holland D, Mekki A, Gee IA, et al. The structure of sodium iron silicate glass - a multi-technique approach. J Non Cryst Solids. 1999;253:192-202.

41. Booth $\mathrm{CH}$, Allen PG, Bucher JJ, et al. Oxygen and phosphorus coordination around iron in crystalline ferric ferrous pyrophosphate and iron-phosphate glasses with $\mathrm{UO}_{2}$ or $\mathrm{Na}_{2} \mathrm{O}$. J Mater Res. 1999;14 (6): p2628-2639.

42. Wright AC, Sinclair RN, Shaw JL, et al. The atomic and magnetic structure and dynamics of iron phosphate glasses. Phys Chem Glas J Glas Sci Technol Part B. 2012;53(6): 227-244.

43. Bingham PA and Barney ER. Structure of iron phosphate glasses modified by alkali and alkaline earth additions: neutron and x-ray diffraction studies. $J$ Physics-Condensed Matter. 2012;24(17): 175403.

44. Brese NE, Okeeffe M. Bond-valence parameters for solids. Acta Crystallogr Sect B. 1991;47(2):192-197. 
Table 1: Glasses compositions, densities and glass transition temperatures

\begin{tabular}{cccc}
\hline Sample & Composition & $\begin{array}{c}\text { Density }\left(\mathrm{g} / \mathrm{cm}^{3}\right) \\
\pm 0.05\end{array}$ & $\begin{array}{c}\mathrm{DSC}\left(\mathrm{T}_{\mathrm{g}}{ }^{\circ} \mathrm{C}\right) \\
\pm 5^{\circ} \mathrm{C}\end{array}$ \\
\hline $10 \mathrm{Fe}$ & $30 \% \mathrm{Na}_{2} \mathrm{O}-10 \% \mathrm{Fe}_{2} \mathrm{O}_{3}-60 \% \mathrm{P}_{2} \mathrm{O}_{5}$ & 2.65 & 381 \\
$20 \mathrm{Fe}$ & $20 \% \mathrm{Na}_{2} \mathrm{O}-20 \% \mathrm{Fe}_{2} \mathrm{O}_{3}-60 \% \mathrm{P}_{2} \mathrm{O}_{5}$ & 2.84 & 481 \\
$30 \mathrm{Fe}$ & $10 \% \mathrm{Na}_{2} \mathrm{O}-30 \% \mathrm{Fe}_{2} \mathrm{O}_{3}-60 \% \mathrm{P}_{2} \mathrm{O}_{5}$ & 2.97 & 527 \\
$40 \mathrm{Fe}$ & $0 \% \mathrm{Na}_{2} \mathrm{O}-40 \% \mathrm{Fe}_{2} \mathrm{O}_{3}-60 \% \mathrm{P}_{2} \mathrm{O}_{5}$ & 3.03 & 498 \\
\hline
\end{tabular}


Table 2: Positions $\left(\mathrm{cm}^{-1}\right)$ of the bands and their assignments of FTIR spectra of the four samples

\begin{tabular}{|c|c|c|}
\hline Wavenumber $\left(\mathrm{cm}^{-1}\right)$ & Assignment & $\begin{array}{l}\text { Trend of intensity } \\
\text { with increasing Fe } \\
\text { content }\end{array}$ \\
\hline $480-530$ & $\begin{array}{l}\text { Bending harmonics of O-P-O } \\
\text { units with } \mathrm{Fe} \text { as modifier }\end{array}$ & Constant \\
\hline $700-780$ & $\begin{array}{l}\text { Symmetric stretches of P-O-P } \\
\text { bridge corner shared in } Q^{1} \\
\qquad\left(\mathrm{P}_{2} \mathrm{O}_{7}\right)^{4-} \text { units }\end{array}$ & Decreasing \\
\hline $900-941$ & $\begin{array}{l}\text { Asymmetric stretching } \\
\text { vibrations of P-O-P }\end{array}$ & $\begin{array}{l}\text { Shift to higher } \\
\text { frequency }\end{array}$ \\
\hline 960 & $Q^{O}\left(\mathrm{PO}_{4}\right)^{3-}$ & $\begin{array}{l}\text { Shift to higher } \\
\text { frequency }\end{array}$ \\
\hline $1078-1178$ & Vibrations of ${\mathrm{P}-\mathrm{O}^{-} \text {group }}$ & Constant \\
\hline $1245-1282$ & $\begin{array}{c}\text { Asymmetric stretching } \\
\text { vibrations of two } \mathrm{O}_{\mathrm{nb}} \text { in }\left(\mathrm{PO}_{2}\right) \text { or } \\
Q^{2}\end{array}$ & Decreasing \\
\hline
\end{tabular}


Table 3: Structural parameters obtained from the fitting of $\mathrm{X}$-ray and neutron diffraction data

\begin{tabular}{|c|c|c|c|c|c|c|c|}
\hline \multirow[t]{2}{*}{ Sample } & \multirow[t]{2}{*}{ Correlation } & \multicolumn{3}{|c|}{ X-ray diffraction } & \multicolumn{3}{|c|}{ Neutron diffraction } \\
\hline & & $\begin{array}{c}\mathrm{R} / \AA \\
( \pm 0.02)\end{array}$ & $\begin{array}{c}\mathrm{N} \\
( \pm 0.2)\end{array}$ & $\begin{array}{c}\sigma / \AA \\
( \pm 0.01)\end{array}$ & $\begin{array}{c}\mathrm{R} / \AA \\
( \pm 0.02)\end{array}$ & $\begin{array}{c}\mathrm{N} \\
( \pm 0.2)\end{array}$ & $\begin{array}{c}\sigma / \AA \\
( \pm 0.01)\end{array}$ \\
\hline \multirow[t]{8}{*}{$10 \mathrm{Fe}$} & $\mathrm{P}-\mathrm{O}$ & 1.54 & 4.1 & 0.05 & 1.49 & 1.9 & 0.08 \\
\hline & $\mathrm{P}-\mathrm{O}$ & - & - & - & 1.58 & 2.0 & 0.09 \\
\hline & $\mathrm{FeO}$ & 2.00 & 5.7 & 0.06 & 1.98 & 5.5 & 0.11 \\
\hline & $\mathrm{Na}-\mathrm{O}$ & 2.33 & 5.0 & 0.15 & 2.30 & 5.0 & 0.15 \\
\hline & $\mathrm{O}-\mathrm{O}$ & 2.51 & 4.0 & 0.06 & 2.52 & 3.8 & 0.10 \\
\hline & P-P & 2.89 & 1.9 & 0.09 & 2.88 & 2.0 & 0.07 \\
\hline & $\mathrm{O}-\mathrm{O}$ & 2.99 & 6.0 & 0.22 & 3.05 & 5.9 & 0.21 \\
\hline & Fe-P & 3.20 & 6.0 & 0.15 & 3.50 & 4.0 & 0.08 \\
\hline \multirow[t]{8}{*}{$20 \mathrm{Fe}$} & $\mathrm{P}-\mathrm{O}$ & 1.55 & 4.1 & 0.06 & 1.50 & 2.1 & 0.07 \\
\hline & $\mathrm{P}-\mathrm{O}$ & - & - & - & 1.58 & 1.8 & 0.08 \\
\hline & $\mathrm{FeO}$ & 1.99 & 5.4 & 0.05 & 1.98 & 5.1 & 0.10 \\
\hline & $\mathrm{Na}-\mathrm{O}$ & 2.34 & 5.0 & 0.11 & 2.24 & 5.1 & 0.09 \\
\hline & $\mathrm{O}-\mathrm{O}$ & 2.50 & 3.9 & 0.08 & 2.51 & 3.7 & 0.10 \\
\hline & P-P & 2.90 & 1.9 & 0.12 & 2.89 & 1.8 & 0.10 \\
\hline & $\mathrm{O}-\mathrm{O}$ & 3.00 & 6.0 & 0.22 & 2.98 & 5.8 & 0.25 \\
\hline & Fe-P & 3.28 & 6.2 & 0.18 & 3.28 & 6.4 & 0.11 \\
\hline \multirow[t]{8}{*}{$30 \mathrm{Fe}$} & $\mathrm{P}-\mathrm{O}$ & 1.54 & 4.0 & 0.06 & 1.52 & 2.3 & 0.07 \\
\hline & $\mathrm{P}-\mathrm{O}$ & & & & 1.59 & 1.6 & 0.09 \\
\hline & $\mathrm{FeO}$ & 1.97 & 5.2 & 0.06 & 1.97 & 5.2 & 0.12 \\
\hline & $\mathrm{Na}-\mathrm{O}$ & 2.36 & 4.8 & 0.11 & 2.23 & 5.0 & 0.08 \\
\hline & $\mathrm{O}-\mathrm{O}$ & 2.49 & 4.0 & 0.10 & 2.52 & 3.9 & 0.11 \\
\hline & P-P & 2.94 & 1.6 & 0.04 & 2.89 & 1.5 & 0.07 \\
\hline & $\mathrm{O}-\mathrm{O}$ & 2.84 & 6.0 & 0.29 & 3.00 & 6.0 & 0.22 \\
\hline & Fe-P & 3.28 & 6.5 & 0.16 & 3.40 & 6.0 & 0.13 \\
\hline \multirow[t]{3}{*}{$40 \mathrm{Fe}$} & $\mathrm{P}-\mathrm{O}$ & 1.52 & $3.6 \pm 0.02$ & - & 1.53 & $3.9 \pm 0.3$ & - \\
\hline & $\mathrm{FeO}$ & 1.93 & $4.6 \pm 0.3$ & - & 1.94 & $5.0 \pm 0.5$ & - \\
\hline & $\mathrm{O}-\mathrm{O}$ & 2.45 & $5.0 \pm 0.5$ & - & 2.53 & $5.0 \pm 0.5$ & - \\
\hline
\end{tabular}


Table 4: Fe K-edge EXAFS-derived structural parameters from beamlines $\mathrm{X} 1$ and A1. Reasonable estimates of errors are $\pm 0.02 \AA$ in $R, \pm 20 \%$ in $N$ and $A$. The italic numbers mean that these values have been fixed during the fitting.

\begin{tabular}{|c|c|cccc|cccc|}
\hline Sample & Correlation & \multicolumn{5}{|c|}{ Beamline X1 } & \multicolumn{5}{|c|}{ Beamline A1 } \\
\cline { 3 - 10 } & & $\begin{array}{c}\mathrm{R} \\
(\AA)\end{array}$ & $\mathrm{N}$ & $\begin{array}{c}\mathrm{A} / \\
\left(\AA^{2}\right)\end{array}$ & $\mathrm{R} \%$ & $\begin{array}{c}\mathrm{R} \\
(\AA)\end{array}$ & $\mathrm{N}$ & $\begin{array}{c}\mathrm{A} / \\
\left(\AA^{2}\right)\end{array}$ & $\mathrm{R} \%$ \\
& & & & & & & & & \\
\hline $10 \mathrm{Fe}$ & $\mathrm{Fe}-\mathrm{O}$ & 1.98 & 5.7 & 0.014 & 12.3 & 1.98 & 5.7 & 0.013 & 20.6 \\
& $\mathrm{Fe}-\mathrm{P}$ & 3.20 & 2.5 & 0.010 & & 3.20 & 2.0 & 0.010 & \\
& & & & & & & & & \\
\hline $20 \mathrm{Fe}$ & $\mathrm{Fe}-\mathrm{O}$ & 1.97 & 5.5 & 0.015 & 18.5 & 1.96 & 5.2 & 0.014 & 21.0 \\
& $\mathrm{Fe}-\mathrm{P}$ & 3.19 & 1.9 & 0.010 & & 3.16 & 1.5 & 0.010 & \\
& & & & & & & & & \\
\hline $30 \mathrm{Fe}$ & $\mathrm{Fe}-\mathrm{O}$ & 1.95 & 5.3 & 0.016 & 23.5 & 1.96 & 4.8 & 0.016 & 25.0 \\
& $\mathrm{Fe}-\mathrm{P}$ & 3.17 & 1.4 & 0.010 & & 3.16 & 1.0 & 0.010 & \\
& & & & & & & & & \\
\hline $40 \mathrm{Fe}$ & $\mathrm{Fe}-\mathrm{O}$ & 1.90 & 4.5 & 0.014 & 20.0 & 1.90 & 4.0 & 0.015 & 32.0 \\
& $\mathrm{Fe}-\mathrm{P}$ & 3.22 & 2.7 & 0.015 & & 3.22 & 2.3 & 0.015 & \\
& $\mathrm{Fe}-\mathrm{Fe}$ & 3.52 & 1.7 & 0.015 & & 3.51 & 1.6 & 0.015 & \\
& & & & & & & & & \\
\hline
\end{tabular}


Figure 1: FTIR spectra for the four samples

Figure 2: XRF spectra for the three samples

Figure 3: The relationship between the theoretical and experimental Fe/P ratio

Figure 4: The $Q$-space interference function, $i(Q)$, obtained from neutron diffraction (top) and X-ray (bottom). The dashed lines in ND data represent the data before removing magnetic scattering. In ND each graph has been shifted by 0.2 , while the $\mathrm{X}$-ray $i(Q)$ has been shifted by 0.4 , for clarity.

Figure 5: The total correlation function T(r) from ND (top) and XRD (bottom) (solid line) together with fit (dashed line). Each ND graph has been shifted by 2, while XRD has been shifted by 10 , for clarity.

Figure 6: Fe K-edge XANES spectra for the samples and the crystal standards samples from beamline X1.

Figure 7: Fe K-edge XANES spectra for the samples and the crystal standards samples from beamline A1.

Figure 8: The Fe K-edge $k^{3}$ weighted EXAFS spectra of the samples (from beamline X1). The solid lines are the experimental data and the dashed lines are the theoretical fits.

Figure 9: The Fourier transform of the Fe K-edge $k^{3}$ weighted EXAFS spectra of the samples (from beamline X1). The solid lines are the experimental data and the dashed lines are the theoretical fits.

Figure 10: The Fe K-edge $k^{3}$ weighted EXAFS spectra of the samples (from beamline A1). The solid lines are the experimental data and the dashed lines are the theoretical fits.

Figure 11: The Fourier transform of the Fe K-edge $k^{3}$ weighted EXAFS data of the samples (from beamline A1). The solid lines are the experimental data and the dashed lines are the theoretical fits. 


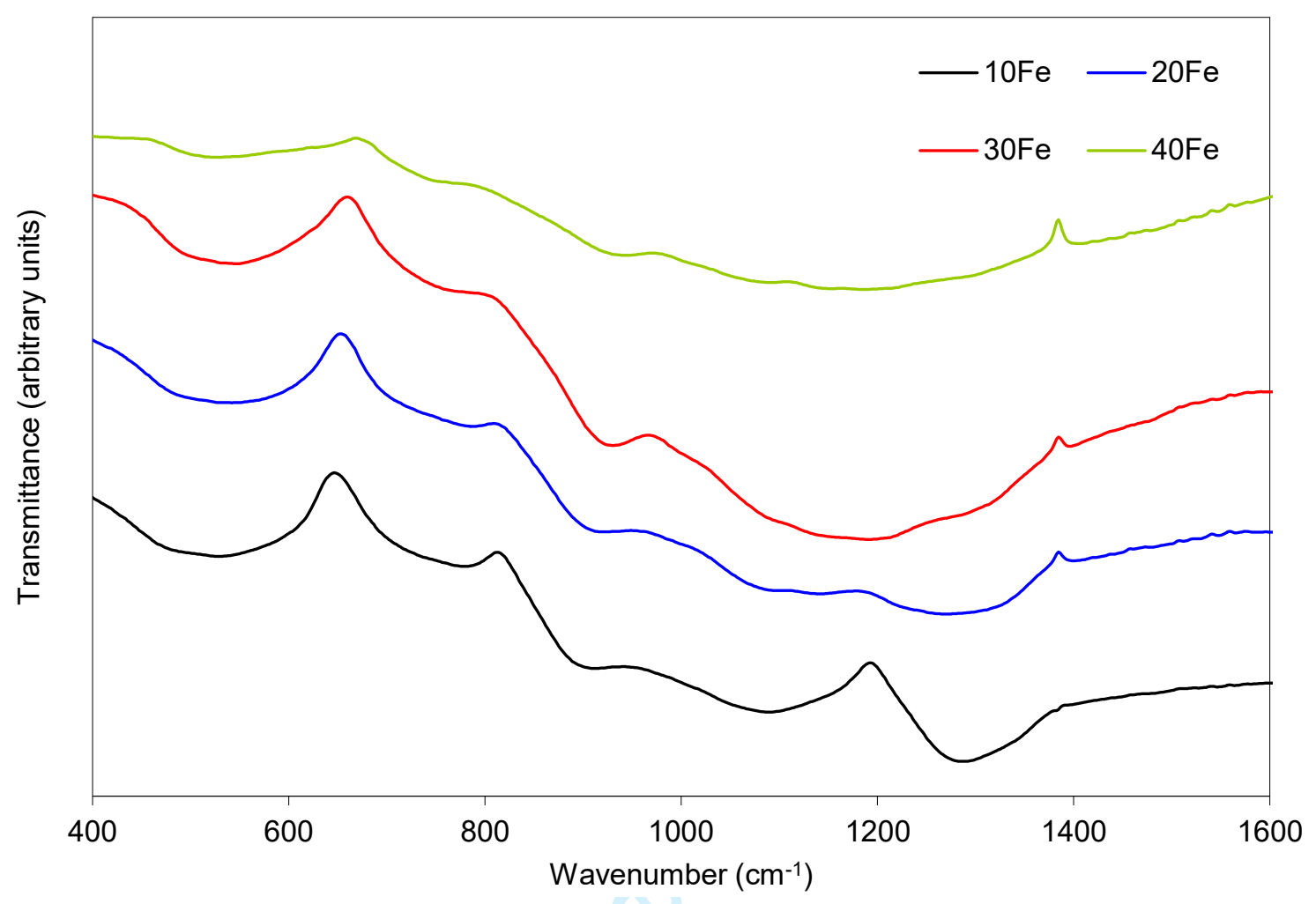

Figure 1 : FTIR spectra for the four samples 


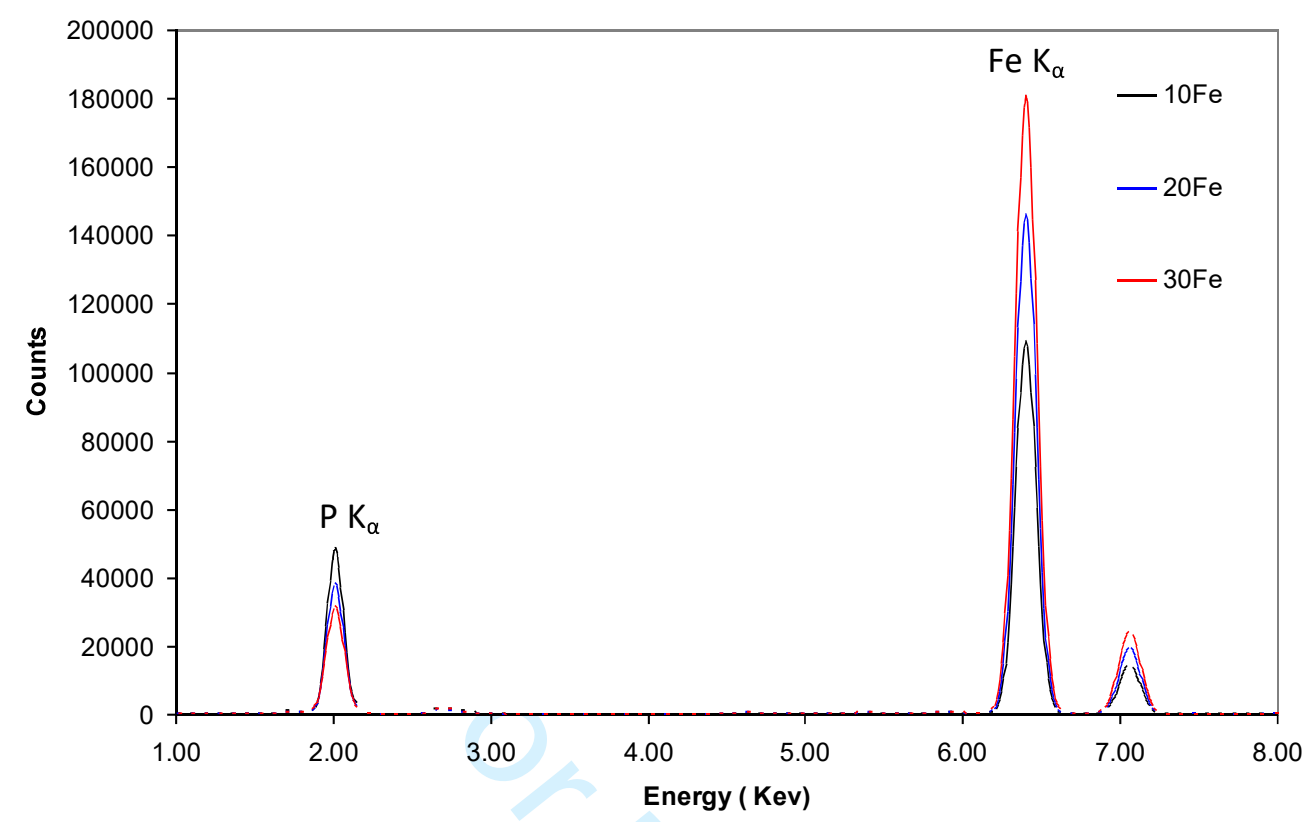

Figure 2: XRF spectra for the three samples

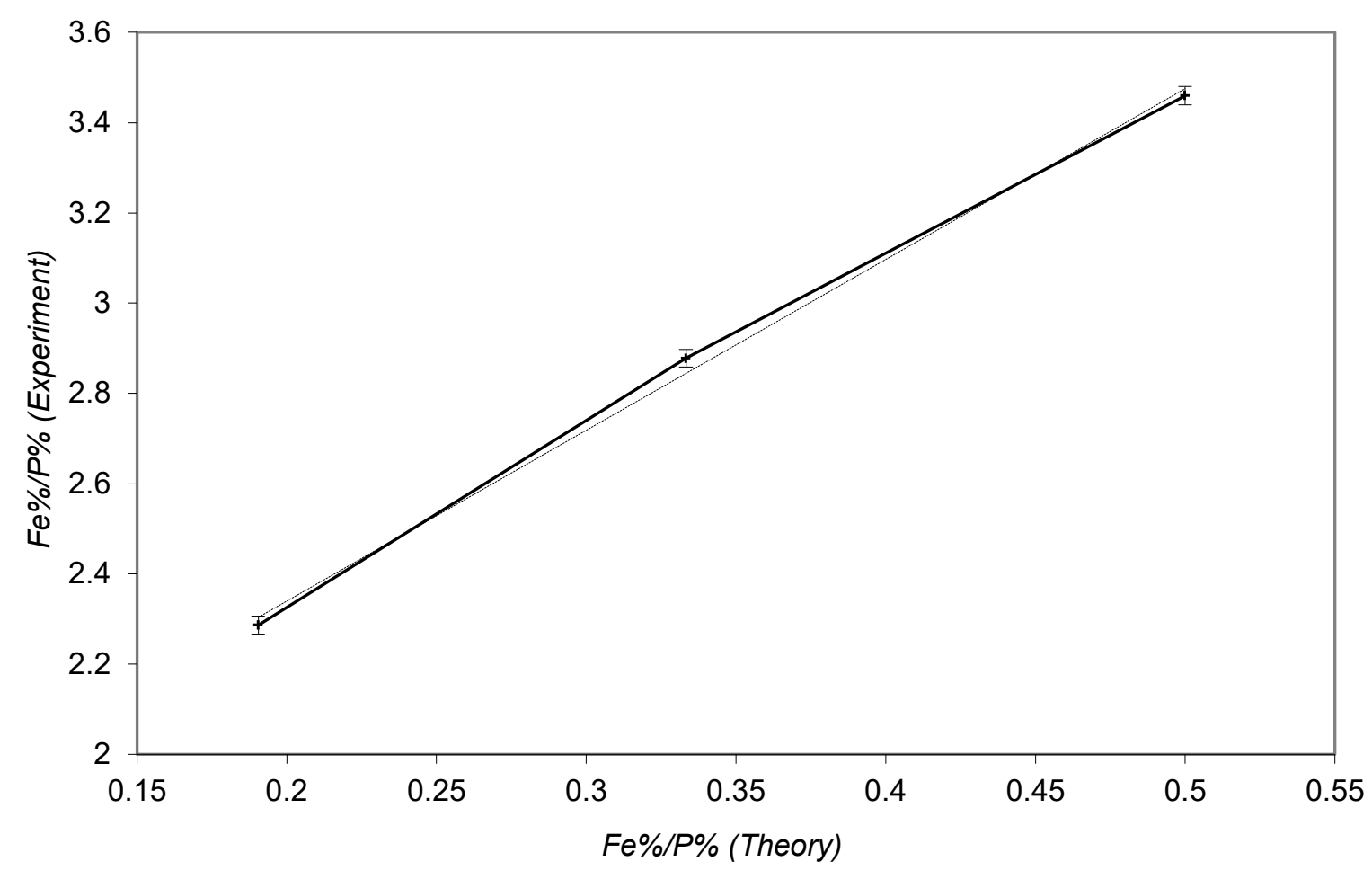

Figure 3: The relationship between the theoretical composition and experimental counts for $\mathrm{Fe} / \mathrm{P}$ ratio 



Figure 4: The $Q$-space interference function, $i(Q)$, obtained from neutron diffraction (top) and X-ray (bottom). The dashed lines in ND data represent the data before removing magnetic scattering. In ND each graph has been shifted by 0.2 for clarity, while the X-ray $i(Q)$ has been shifted by 0.4 for clarity. 

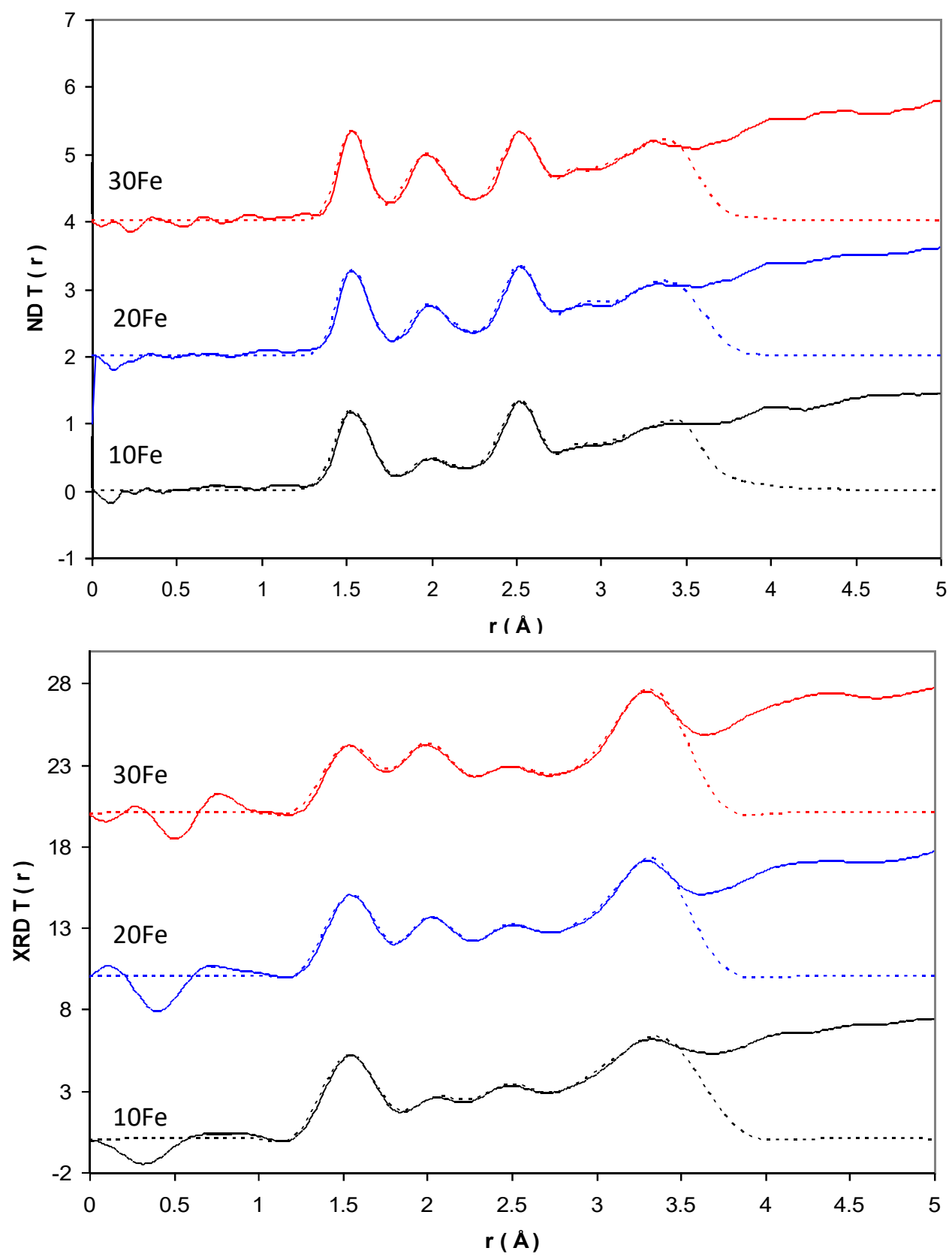

Figure 5: The total correlation function T(r) from ND (top) and XRD(bottom) (solid line) together with fit (dashed line). Each NDgraph has been shifted by 2 for while XRD has been shifted by 10 clarity. 


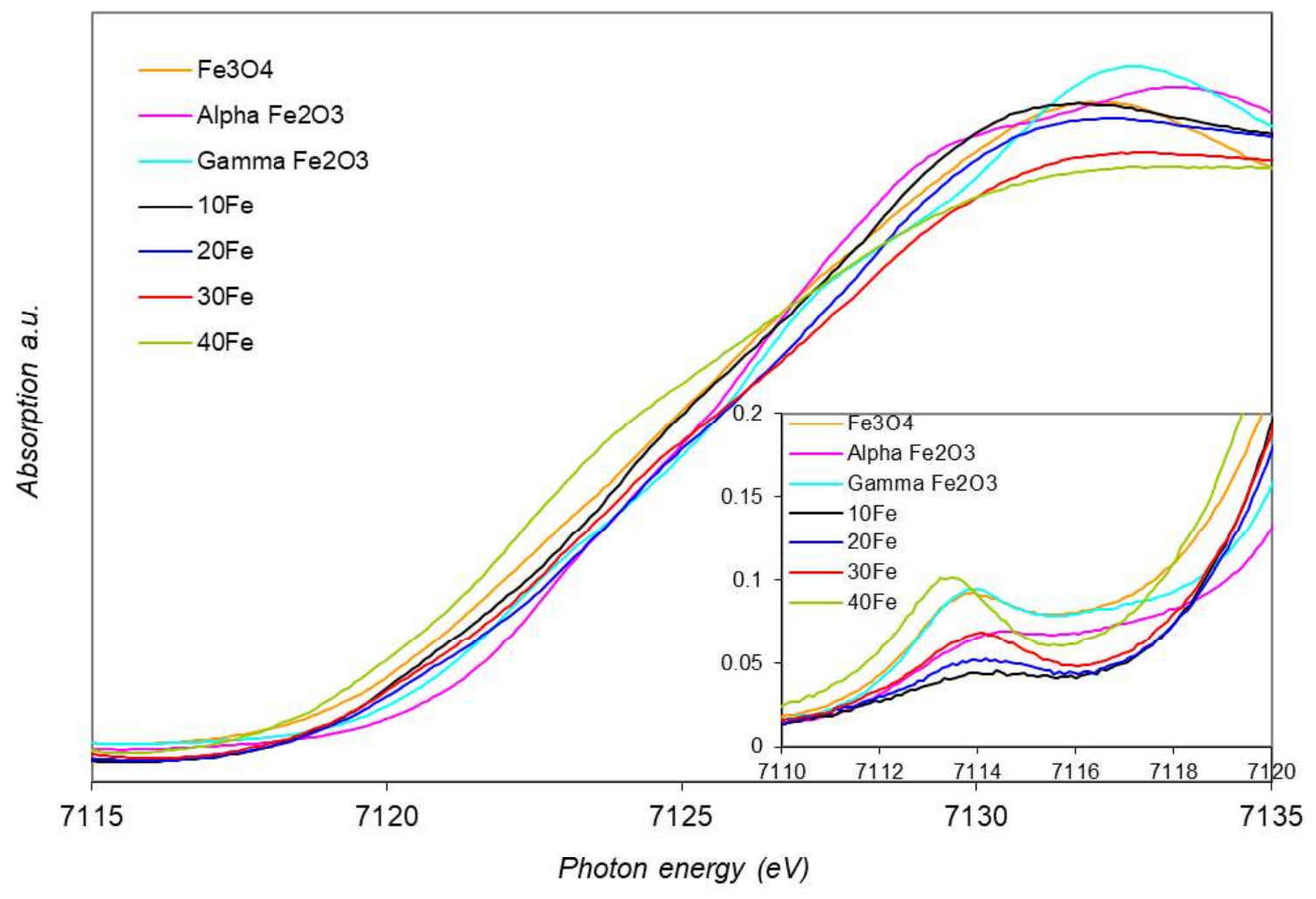

Figure 6: Fe K-edge XANES spectra for the samples and the standards crystal samples from beam line X1. 


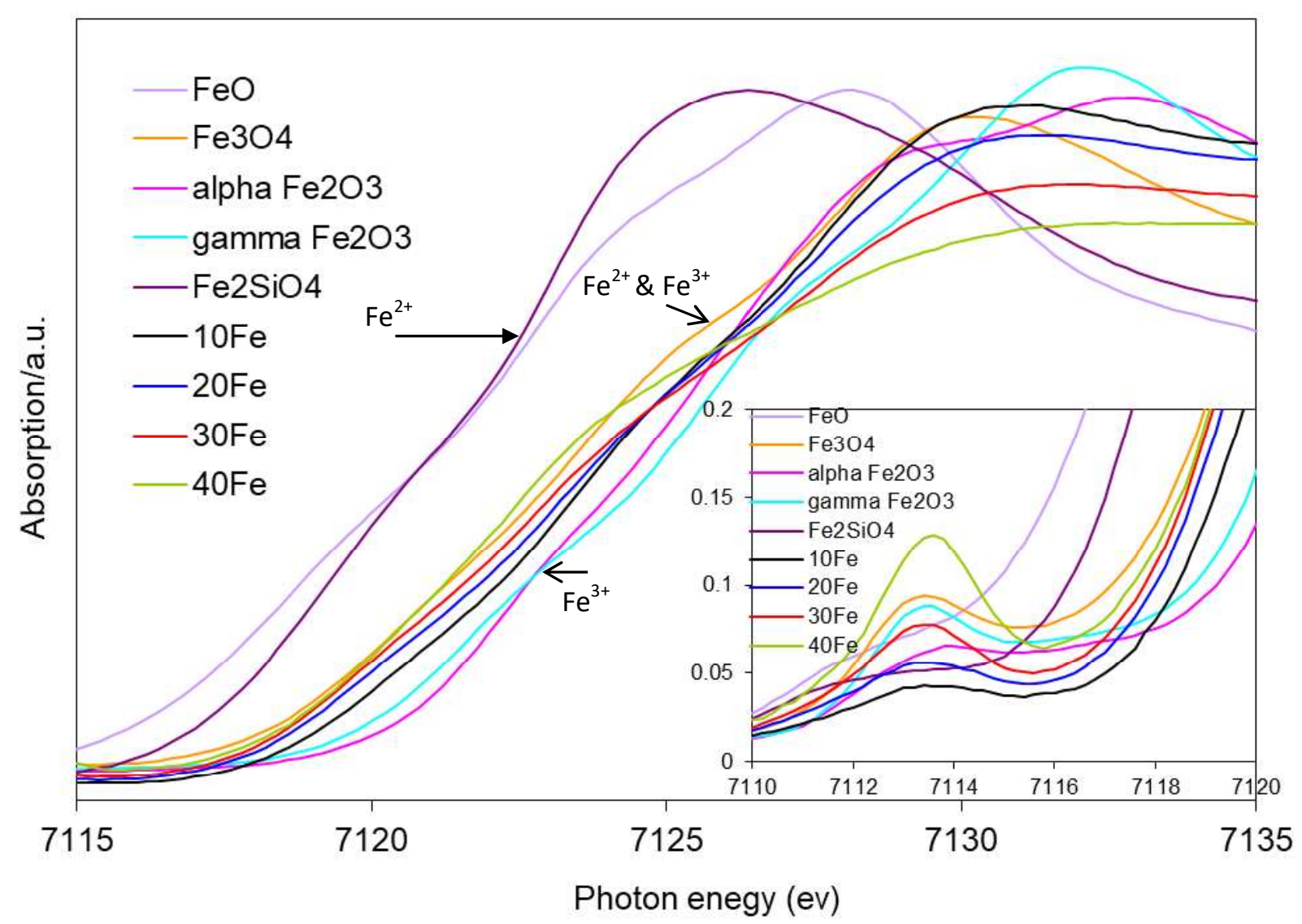

Figure 7: Fe K-edge XANES spectra for the samples and the standards crystal samples from beam line A1. 




Figure 8: The Fe K-edge $k^{3}$ weighted EXAFS spectra of the samples (from beamline $\mathrm{X} 1)$. The solid lines are the experimental data and the dashed lines are the theoretical fits.

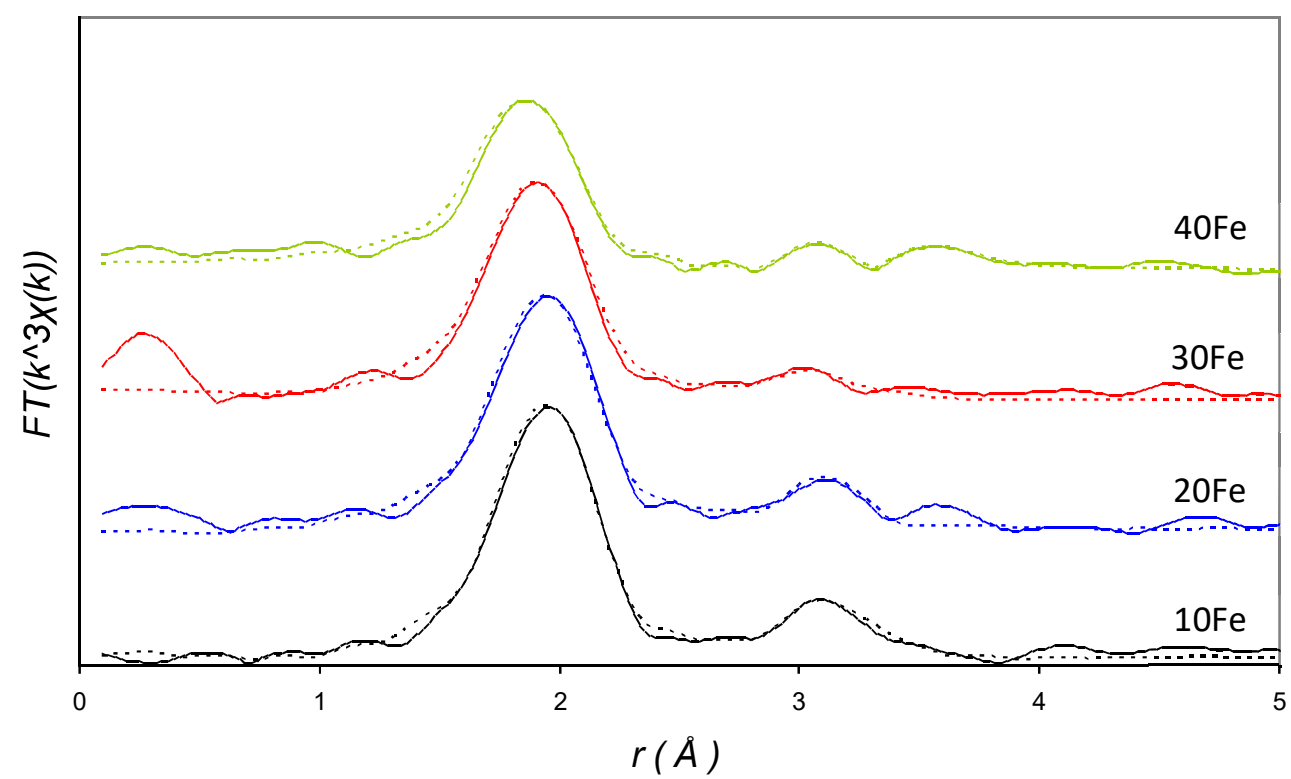

Figure 9: The Fourier transform of the Fe K-edge $k^{3}$ weighted EXAFS spectra of the samples (from beamline X1). The solid lines are the experimental data and the dashed 
lines are the theoretical fits.

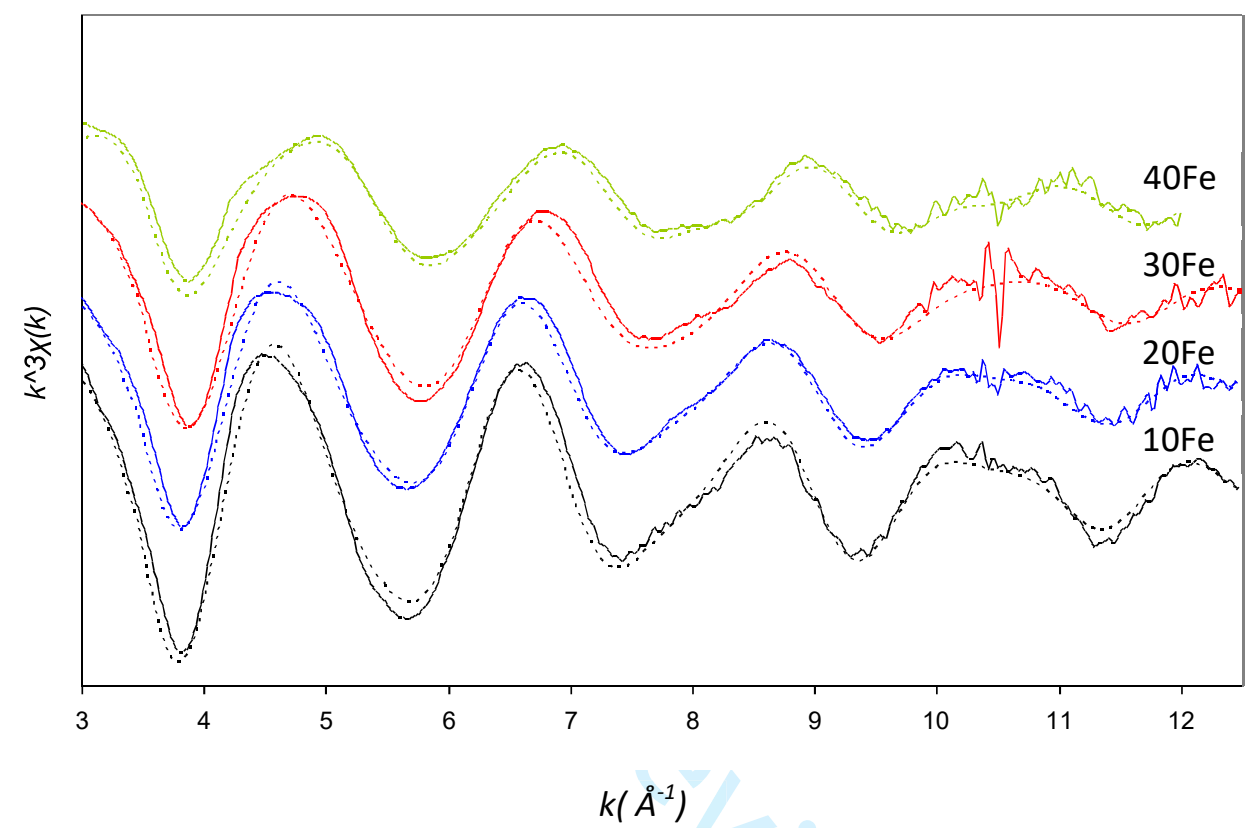

Figure 10: The Fe K-edge $k^{3}$ weighted EXAFS spectra of the samples (from beamline A1). The solid lines are the experimental data and the dashed lines are the theoretical fits.

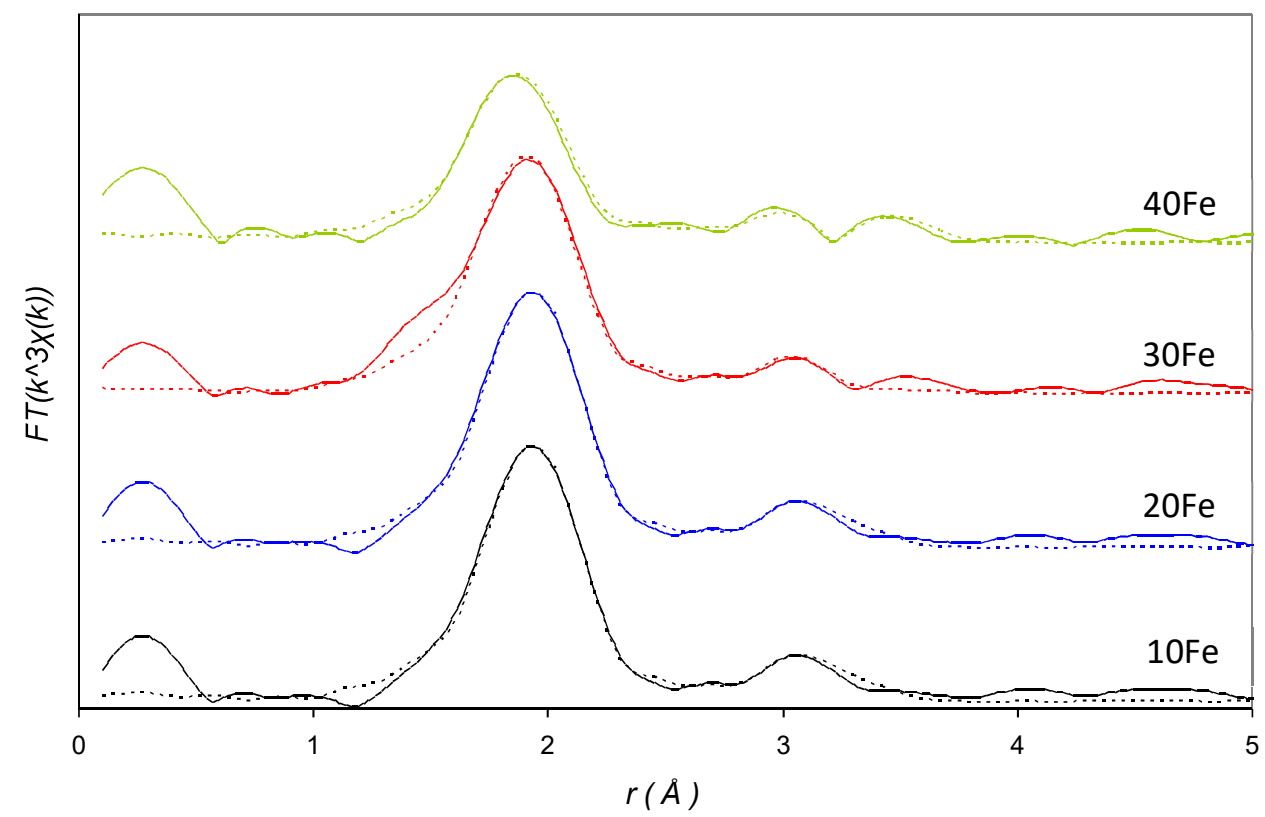


Figure11: The Fourier transform of the Fe K-edge $k^{3}$ weighted EXAFS data of the samples (from beamline A1). The solid lines are the experimental data and the dashed lines are the theoretical fits. 